\title{
Early Unilateral Deprivation Modifies Olfactory Bulb Function
}

\author{
K. M. Guthrie, D. A. Wilson, ${ }^{a}$ and M. Leon \\ Department of Psychobiology, University of California at Irvine, Irvine, California 92717
}

\begin{abstract}
Unilateral olfactory deprivation during postnatal development produces significant structural and neurochemical modifications of the olfactory bulb. In the present report, we describe the functional consequences of such deprivation. Rat pups had a single naris occluded on postnatal day 2 (PN2) to deprive them of early olfactory stimulation. On PN2022 , the occluded naris was reopened, the previously open naris was sealed, and responses of the deprived olfactory bulb to odors were assessed using both single-unit recording from mitral/tufted cells and quantitative ${ }^{14} \mathrm{C}$-2-deoxyglucose (2-DG) autoradiography. While the response properties of individual odor-stimulated mitral/tufted cells were not altered by early deprivation, spontaneous activity was depressed, and there was a significantly higher incidence of odor-responsive mitral/tufted cells in deprived compared to nondeprived bulbs. In addition, odor-stimulated deprived bulbs demonstrated greater uptake of 2-DG than did nondeprived bulbs. Together, these data indicate that the olfactory system demonstrates an increased responsiveness to sensory cues following early deprivation.
\end{abstract}

The functioning of mature sensory systems is strongly influenced by the sensory environment encountered during perinatal development. This sensitivity to perinatal manipulation has probably been best demonstrated through the use of paradigms in which early sensory deprivation, resulting from either removal of receptors or stimulus blockade, results in marked changes in the structure and function of the deprived system at maturation (e.g., Weisel and Hubel, 1963a, b; Hubel and Wiesel, 1970; Van der Loos and Woolsey, 1973; Garey and Blakemore, 1977; Shatz and Stryker, 1978; Durham and Woolsey, 1984; Knudsen et al., 1984; Moore et al., 1989; Pasic and Rubel, 1989; Robertson and Irvine, 1989).

While much of this research has focused on the visual, auditory, and tactile systems, recent evidence suggests that the mammalian olfactory system is also exquisitely sensitive to postnatal deprivation. Unilateral naris occlusion at birth results in a $25 \%$ reduction in the size of the ipsilateral rat olfactory bulb and a decrease in the size and number of most types of bulb neurons (Meisami and Safari, 1981; Benson et al., 1984; Skeen et al., 1985, 1986; Meisami and Noushinfar, 1986; Frazier

\footnotetext{
Received Dec. 4, 1989; revised June 4, 1990; accepted June 8, 1990.

This research was supported by NSF grant BNS 8606786 to D.A.W. and M.L and by NICHD grant HD24236 to M.L., who also holds RSDA MH-00371 from NIMH.

Correspondence should be addressed to Kathleen M. Guthrie, Department of Anatomy and Neurobiology, University of California, Irvine, CA 92717.

a Present address: Developmental Psychobiology Laboratory, Department of Psychology, University of Oklahoma, Norman, OK 73019.

Copyright (C) 1990 Society for Neuroscience $0270-6474 / 90 / 103402-11 \$ 03.00 / 0$
}

and Brunjes, 1988). Olfactory deprivation also results in decreased olfactory bulb dopamine content and reduced immunoreactivity for tyrosine hydroxylase (TH; the rate-limiting enzyme in the catecholamine biosynthetic pathway) in juxtaglomerular neurons (Brunjes et al., 1985; Baker, 1986; Kosaka et al., 1987). In addition, there is an upregulation of glomerular-layer dopamine- (spiperone, D2) and NGF-binding sites in the deprived bulb (Guthrie et al., 1987; Gomez-Pinilla et al., 1989). Tonic bulbar metabolic activity, as judged by histochemical staining for succinic dchydrogenase and cytochrome oxidase, is also diminished following early deprivation (Cullinan and Brunjes, 1987).

Although early olfactory deprivation results in these robust changes in olfactory bulb neuroanatomy and neurochemistry, the effects of deprivation on bulb function have not been studied. We therefore examined how postnatal olfactory deprivation influences the functional development of the olfactory bulb. Neonatal rat pups were unilaterally deprived of olfactory stimulation by naris occlusion during the first 3 postnatal weeks. The sealed naris was then reopened to test the odor responses of the deprived olfactory bulb. Deprivation was limited to the first 3 postnatal weeks in order to permit examination of bulb function at a time when TH immunoreactivity in glomerular neurons was significantly reduced, but prior to the major occurrence of deprivation-induced cell death (Meisami and Safari, 1981; Frazicr and Brunjes, 1988).

We evaluated 2 indices of olfactory bulb function. First, odorstimulated activity in the deprived bulb was assessed using methods to quantitate ${ }^{14} \mathrm{C}$-2-deoxyglucose (2-DG) autoradiographs. Exposure to odors produces odor-specific spatial patterns of focal 2-DG uptake in the glomerular layer (GL) of the normal olfactory bulb (Sharp et al., 1975; Stewart et al., 1979; Jourdan et al., 1980; Royel et al., 1987). Second, we examined single-unit odor responses of mitral/tufted cells in the deprived bulb. To verify that naris occlusion had effectively limited olfactory stimulation during postnatal development, pups used for neurophysiological testing were perfused after the recording session, and their bulbs were examined for changes in $\mathrm{TH}$ immunoreactivity. The results demonstrate that early unilateral deprivation significantly modifies olfactory bulb function, primarily by increasing responsiveness to olfactory stimulation.

\section{Materials and Methods}

Subjects. Male Wistar rat pups born in our colony and raised in litters of 8 pups were used in all experiments ( $d$ of birth = postnatal $\mathrm{d} 0, \mathrm{PNO}$ ). At PN2, pups were cold anesthetized, and the left or right naris was cauterized (see Meisami, 1976). Two undeprived control pups from each litter were cauterized on the top of the snout. Xylocaine was applied topically to the cauterized region, and the pups were allowed to recover on a heating pad prior to returning them to the dams. Physiological comparisons were not made between the deprived and undeprived bulbs 
in the same animals due to the influence of commissural connections on olfactory bulb physiology and the unknown effects of unilateral deprivation on these connections (Nakashima et al., 1978; Mori et al., 1979; Math and Davrainvilie, 1980).

On PN20-22, pups were used for either 2-DG autoradiography or single-unit recording and TH immunohistochemistry. Only deprived pups that exhibited complete naris occlusion upon visual inspection of the scar tissue were used. All procedures (2-DG, recording, perfusion) were completed within $7 \mathrm{~h}$ after naris opening.

2-Deoxyglucose autoradiography. Three groups of animals were tested (Fig. 1). The first group consisted of control littermates, which allowed us to evaluate normal bulb 2-DG uptake in response to odor or room air (normal control group, $n=6$ ). Experimental animals in the surgically reopened group $(n=6)$ respired through only 1 nostril during the odor test, and forced unilateral respiration, apart from deprivation effects, might contribute to changes in bulb 2-DG uptake. To address this possibility, a third group of animals remained surgically occluded while exposed to peppermint odor (deprived group, $n=5$ ). This allowed us to compare 2-DG uptake in normal, nondeprived bulbs under both test conditions, that is, with only the single, ipsilateral naris open or with both nares open. To evaluate the effects of unilateral naris closure on respiration, the respiratory patterns of all animals were recorded during the test period. The testing apparatus consisted of an air-tight glass jar with odor input and output ports, equipped with a pressure-sensitive transducer. The interval between successive respirations was recorded by a respiration monitor (Columbus Instruments) and sorted by an online computer into frequency bins of 50-msec duration (see Coopersmith and Leon, 1984).

On PN20-22, all pups were anesthetized with Ketaset-Rompun (1:1 mixture, $25 \mathrm{mg} / \mathrm{kg}$, i.p.). For animals in the reopened group, the occluded naris was surgically opened. Microsurgical scissors were used to cut through the overlying scar tissue and a 4-mm section of PE160 tubing $(1.14 \mathrm{~mm}$, i.d.) was inserted snugly into the newly opened nasal passage to ensure patency. The tubing was inserted just far enough to ensure that it did not protrude from the naris. Bleeding was minimal and care was taken to maintain the reopened naris free of fluid.

Preliminary studies indicated that somc of thesc animals failcd to respire via the reopened naris for prolonged periods unless the contralateral, normal naris was sealed. As rats are obligate nose breathers, respiration then occurs entirely through the newly opened nasal passage. Therefore, the normal naris was occluded by first depositing petroleum jelly just inside the naris, using a syringe with a blunted 26 -gauge needle Collodion was then applied over the outside of the naris (reopened group). Normal control littermates had collodion applied to the top of the snout, as did littermates that remained surgically occluded (deprived group) during the subsequent odor test (see Fig. 1).

After awakening, all animals were allowed to completely recover for an additional $2-5 \mathrm{hr}$, at which time they were injected with ${ }^{14} \mathrm{C}-2-\mathrm{DG}$ ( $20 \mu \mathrm{Ci} / 100 \mathrm{gm}$, s.c.; Sigma) and exposed to room air (nondeodorized), peppermint odor (Schilling), or isoamyl acetate odor (Sigma) for 45 min. Odor concentration was a 1:10 dilution of saturated vapor delivered at a flow rate of 2 liters $/ \mathrm{min}$ for $1 \mathrm{~min}$ at 4.5 -min intervals. Following the odor test, all animals were decapitated, the bulbs quickly removed on ice and frozen in Freon $\left(-50^{\circ} \mathrm{C}\right)$, and the collodion plugs examined to verify occlusion. Several animals in the reopened group were also examined to evaluate placement of the tubing, and in these animals, the tubing did not contact the olfactory mucosa. The olfactory bulbs were subsequently sectioned at $20 \mu \mathrm{m}$ in a cryostat $\left(-16^{\circ} \mathrm{C}\right)$, and every third section was collected and exposed to Kodak SB5 $\mathrm{x}$-ray film. Selected tissue autoradiographs were processed for quantitative densitometry as previously described using a computer-assisted imaging system (MCID, Imaging Research Inc.; Coopersmith and Leon, 1984; Wilson and Leon, 1988). Briefly, the computer generated a calibration curve that related the average gray values of radioactive standards (American Radiolabel $\mathrm{Co}$.) to their previously determined ${ }^{14} \mathrm{C}$ content per gm tissuc. It then linearized this function so that all gray values in tissue autoradiograms could be converted to represent the quantity of ${ }^{14} \mathrm{C}-2-\mathrm{DG}$ incorporated per gm tissue. Sections of interest were later stained with Cresyl violet.

For quantitative comparisons, an average of 8 coronal-tissue autoradiograms (minimum of 5) were analyzed for each animal. Odor stimulation results in scattered areas of high 2-DG uptake in the GL, and different odors produce different distributions of these foci. Tissue autoradiograms from odor-exposed animals were selected for analysis when they contained clearly evident odor-responsive foci in the GL. Auto-

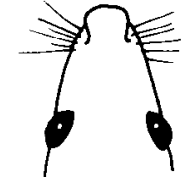

Normal Control Group

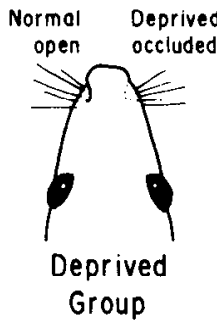

Figure 1. Diagrammatic representation of the 3 groups of animals given ${ }^{14} \mathrm{C}$-2-DG prior to odor exposure. Unilateral naris occlusion was performed by cauterization at PN2. Naris reopening was accomplished surgically at PN20-22, prior to odor testing. The reopened naris was maintained with a small piece of polyethylene tubing.

radiograms from air-exposed animals were chosen from comparable portions of the bulb. Measurements were made in the periventricular corc (PVC), in odor-rcsponsive areas of the GL, in nonresponsive areas (background) of the GL, and in the olfactory nerve layer (ONL); (see Fig. 2). These values were averaged over all sections to obtain mean 2-DG uptake values for each animal. Changes in uptake were expressed as percent differences between bulbs within an individual animal. Analysis of 2-DG uptake in the PVC region of all animals showed no significant differences either within animals $[F(1,26)=0.01, \mathrm{NS}]$ or across experimental groups $[F(2,26)=0.12$, NS $]$. To facilitate comparisons across groups and to minimize errors in quantification due to variable section thickness, nonuniformity of background illumination, or film variability, the relative amount of $2-D G$ uptake was calculated by dividing the uptake values in outer bulb laminae by the PVC. uptake. Means of relative 2-DG uptake for individual animals were used to determine group mean values. Drawings of serial autoradiograms displaycd on the imaging monitor were made to facilitate construction of bulb "odor maps," which allowed comparison of uptake patterns across groups. Photographs of 2-DG autoradiograms were printed directly from the $\mathrm{x}$-ray film.

Neurophysiological analyses. Two groups of animals were tested: those subject to naris reopening and control littermates. On PN20-22, all pups were anesthetized with urethane $(1.5 \mathrm{gm} / \mathrm{kg})$. For animals in the experimental group, the occluded naris was reopened as described above. The contralateral open naris was occluded with petroleum jelly only. The anesthetized pups did not require collodion application as they could not dislodge the petroleum jelly. The animals were then mounted in a stereotaxic holder, and their body temperature was maintained at $34^{\circ} \mathrm{C}$ with a thermostatically controlled heating pad. A single bipolar stimulating electrode was placed in the ipsilateral lateral olfactory tract (LOT), and a glass recording microelectrode filled with $2 \mathrm{M} \mathrm{NaCl}$ was lowered into the ipsilateral olfactory bulb. Mitral/tufted cells were identified by LOT evoked-response morphology and by the ability to activate them antidromically (follow 4 pulses at $100 \mathrm{~Hz}$ ) from the pyriform cortex. Single-unit recordings were made from mitral/tufted cells along the medial aspect of the bulbs, as preliminary studies indicated a consistent loss of TH immunoreactivity in the medial GL with deprivation.

Responses of these mitral/tufted cells to odors were examined as previously described (Wilson et al., 1987; Wilson and Leon, 1988). Briefly, odors were delivered to the external nares through glass tubing from flow-dilution olfactometers while the animals respired normally. Peppermint or isoamyl acetate odor concentration was maintained at a 1:10 dilution and presented for 4-sec pulses at a flow rate of 2 liters/ min, with at least $60 \mathrm{sec}$ elapsing between pulses. Mitral/tufted cell rcsponscs to rcpcatcd odor pulses were analyzed with peristimulus-time histograms accumulated over $2-10$ repetitions of each stimulus $(500-$ 1000 -msec bin widths). Spike activity was isolated with an amplitude window discriminator to filter out possible artifacts produced at the onset and offset of the odor stimulus. Responses were categorized as either excitatory, suppressive, or no response. Excitatory responses were characterized by an increase in firing rate above baseline variability during the stimulus presentation, whereas suppressive responses were characterized by a decrease in firing rate below baseline variability.

Tyrosine hydroxylase immunoreactivity. Olfactory bulb $\mathrm{TH}$ immunoreactivity is rapidly and markedly reduced following olfactory de- 
Figure 2. Photomicrograph of coronal olfactory bulb section from experimental animal, stained with Cresyl violet. The deprived bulb is to the right. $O N L$, olfactory nerve layer; $G L$, glomerular layer; $E$, external plexiform layer; $M$, mitral cell layer; $G$, granule cell layer; $P V C$, periventricular core. Scale bar $=500 \mu \mathrm{m}$.

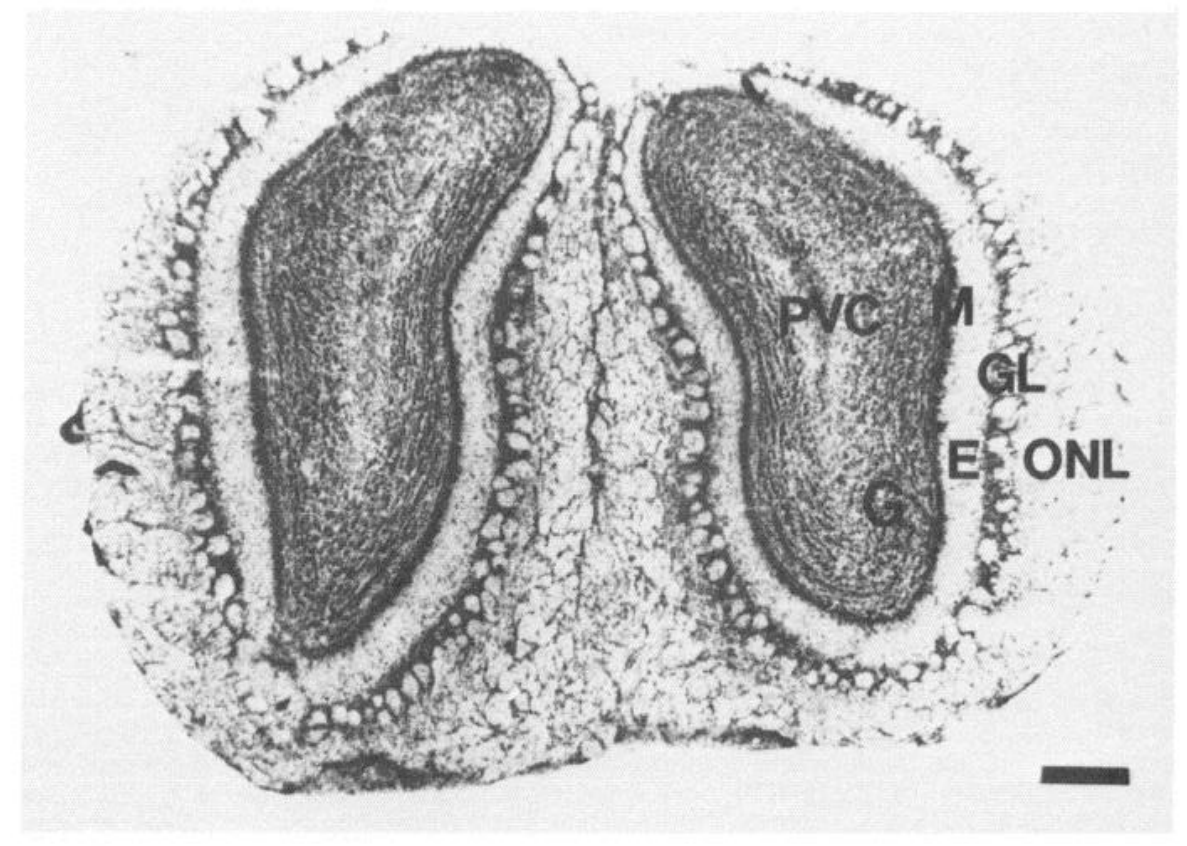

privation (Kosaka et al., 1987; Baker, 1986). In order to determine whether our deprivation procedure effectively altered bulb neurochemistry, the olfactory bulbs of pups used in the neurophysiology study were processed for TH immunostaining following the recording session using affinity-purified rabbit TH antibody (Pel-freez Clinical Systems) and the avidin-HRP-biotin technique (Vector Labs) as previously described (Guthrie and Leon, 1989).

\section{Results}

\section{Morphological effects of olfactory deprivation}

Unilaterally deprived pups tended to be smaller than their agematched, littermate controls on the day of testing (PN20-22). The mean body weight of unilaterally deprived pups was 57.6 gm $( \pm 3.7)$ as compared to $66.2 \mathrm{gm}( \pm 3.6)$ for control pups [paired $t$ test: $t(6)=3.93, p<0.01$ ].

Upon dissection, the deprived olfactory bulb often appeared slightly smaller than the contralateral, nondeprived bulb, as previously reported (Meisami, 1976; Frazier and Brunjes, 1988). However, at PN20, deprivation had not grossly disrupted the organization of bulb laminae (Fig. 2).

\section{2-DG uptake in response to odors}

Surprisingly, analysis of the respiratory patterns of the control, deprived, and reopened groups did not reveal any statistically significant differences $[F(19,160)=0.72-0.89$ for all combinations, NS), though the trend in both of the unilaterally occluded groups was toward fewer total respirations and lower frequencies (e.g., less sniffing) compared to the normal control group (Fig. 3).

Within the normal control group, there were no significant differences between left- and right-bulb laminar 2-DG uptake values [ $2 \times 3$ ANOVA: side effect, $F(1,24)=0.03$, NS; Table 1]. Uptake in the glomerular (background) and nerve layers of normal bulbs from experimental animals (deprived and reopened groups) did not differ significantly from controls under any test condition [i.e., ipsilateral naris open or newly sealed with collodion; $2 \times 3$ ANOVA: group effect, $F(1,24)=0.33$, NS]. Consequently, changes in laminar uptake in deprived bulbs were expressed relative to the contralateral normal bulbs (Table 1). Naris occlusion significantly reduced, but did not completely eliminate, the occurrence of focal uptake in the GL (reopened and deprived groups, solid arrows in Fig. 4B, D). Usually, 1-3 foci were apparent both laterally and medially. These focal areas appeared lightly labeled compared to those seen in normal bulbs, but were occasionally quite prominent. In the weanling rat, the septum that divides the nasal cavities contains an opening (E. Meisami, personal communication). While the activity of centrifugal projections to the bulb may account for the areas of focal uptake seen in bulbs ipsilateral to a sealed naris, we suspect they are the result of a small amount of stimulus crossing over from the contralateral nasal cavity through the septal window or via the nasopharynx. In agreement with previous studies, we also observed focal uptake in the GL of animals exposed to nondeodorized air during the 2-DG test (Sharp et al., 1975; Stewart et al., 1979; Jourdan et al., 1980).

In contrast to the effects of short-term collodion occlusion (reopened group), prolonged surgical occlusion (deprived group) reduced laminar 2-DG uptake in deprived bulbs compared to contralateral normal bulbs [Table 1, Fig. $4 B$; nerve layer: deprived mean uptake $=0.93 \pm 0.04$ vs normal mean uptake $=$ $1.03 \pm 0.08, t(4)=2.30, p=0.08$; GL: deprived mean uptake $=1.50 \pm 0.22$ vs normal mean uptake $=1.73 \pm 0.18, t(4)=$ $7.20, p<0.01]$. Following naris reopening, glomerular and nerve layer 2-DG uptake levels were significantly higher in deprived bulbs compared to contralateral normal bulbs [reopened group; Table 1, Fig. $5 ; 3 \times 3$ ANOVA: group effect, $F(2,39)=13.93$, $p<0.001$ ]. The extent of this increase varied with the test odor, with the largest increase occurring in response to peppermint odor and the least with air. The increases in nerve layer and glomerular uptake were of similar magnitude in animals exposed to isoamyl acetate odor or air, while the average change in glomerular uptake in response to peppermint odor exceeded the increase in nerve layer uptake by $13 \%$. There was no correlation between either animal age (PN20-22) or the length of the postoperative period prior to testing (2-5 hr) and the extent of the enhanced uptake observed. 
Following naris reopening, relative 2-DG uptake in focal regions of the GL was also consistently higher in deprived bulbs compared to contralateral normal bulbs and controls (Figs. 4, $5)$. Again, the enhancement was most apparent in the peppermint/reopened group [ANOVA: $F(2,15)=6.66, p<0.02$ ]. However, because background glomerular uptake also increased, the ratio of focal to nonfocal uptake remained relatively unchanged. Relative uptake in the nerve layer also showed the largest increase in the peppermint/reopened group [ANOVA: $F(2,15)=4.01, p<0.05)$, though both of the other reopened groups demonstrated higher nerve layer uptake as well.

\section{Patterns of uptake}

Patterns of focal 2-DG uptake in the GL were seen in all animals, and different patterns were obtaincd with the 2 different odors. Peppermint exposure typically produced a pattern of 4-8 prominent lateral foci beginning about midway through the rostocaudal extent of the bulb and 3-5 medial foci, which usually occurred more caudally and ventrally. The bulbs of animals exposed to isoamyl acetate odor contained 3-6 lateral foci, which usually began at a more rostral level than did the peppermint foci, and 4-6 medial foci, distributed mostly ventrally, but also occurring at more dorsal levels than did the peppermint foci. While we could discern characteristic bulb-labeling patterns associated with a given odor, the patterns of focal uptake among individual animals varied somewhat. In the deprived group, normal bulbs had patterns of focal uptake in response to peppermint odor similar to control bulbs.

All pups in the reopened groups showed patterns of 2-DG uptake in the GL of the deprived bulb. Variation in individual labeling patterns was grcater for the reopened group compared to the control group, but the areas of focal uptake tended to occur in the same areas of the bulb. For example, peppermint odor tended to produce dorsolateral labeling about midway through the rostrocaudal length of the deprived bulb, and medial labeling at more caudal levels (see Fig. 6). The major difference between deprived and normal bulbs was in the apparent size of the individual odor foci. In most deprived bulbs, these areas of the GL were larger than normal and were fewer in number, as though adjacent odor-responsive areas had coalesced. In several

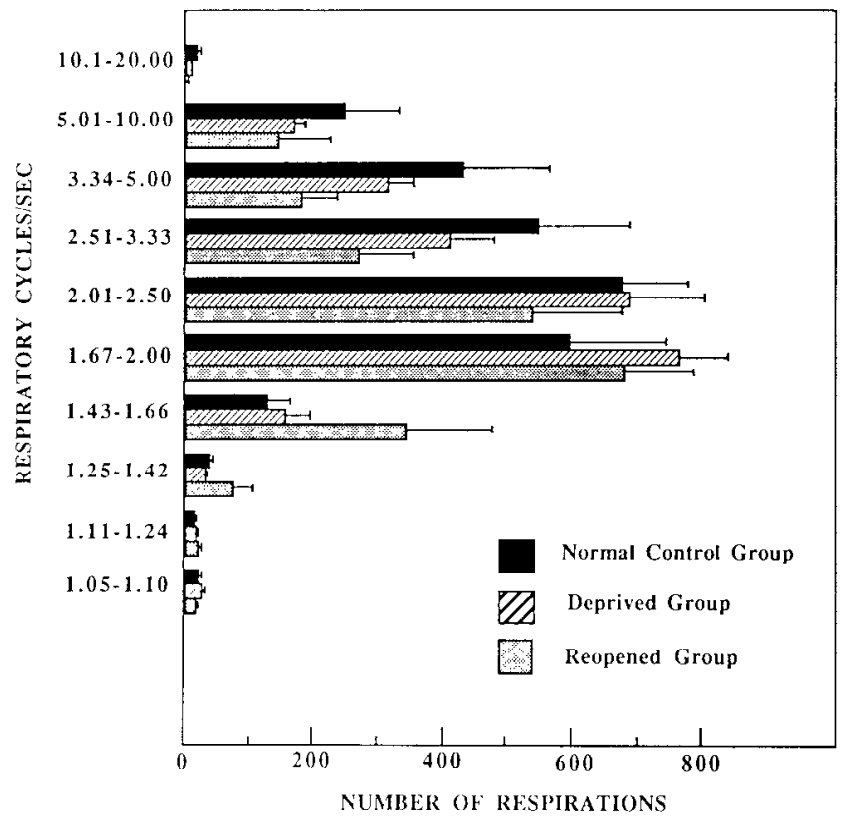

Figure 3. Respiration-frequency histogram for animals exposed to peppermint odor during 45-min test period. See Figure 1 for a complete description of the groups. Mean total respirations during the 45-min test period were 5375 for the control group, 5134 for the deprived group, and 4505 for the reopened group. Lines represent means \pm SEM.

animals, labeling appeared to extend from lateral patches of high 2-DG uptake into surrounding regions of the GL (Fig. 4D). The apparent increase in the relative size of these foci might have resulted from the smaller size of the deprived olfactory bulb, but comparisons of Cresyl violet-stained bulb sections with autoradiograms suggested that odor foci in deprived bulbs encompassed larger areas of the GL than those in normal bulbs.

\section{Mitral/tufted-cell responses to odors}

Single-unit responses to odor presentation were examined from a total of 112 cells ( 61 cells in 10 unilaterally deprived pups and 51 cells in 9 control pups). All recordings were made from cells

Table 1. Mean percent differences in ${ }^{14} \mathrm{C}-2-\mathrm{DG}$ uptake between left and right or deprived and nondeprived olfactory bulbs

\begin{tabular}{lcclr} 
Group/odor & $\begin{array}{l}\text { Olfactory nerve } \\
\text { layer }\end{array}$ & $\begin{array}{l}\text { Background } \\
\text { glomerular layer }\end{array}$ & $\begin{array}{l}\text { Glomerular } \\
\text { layer foci }\end{array}$ & \multicolumn{1}{l}{$\begin{array}{l}\text { Periventricular } \\
\text { core }\end{array}$} \\
\hline Normal control (Pep) & $3.5( \pm 1.4)$ & $2.9( \pm 0.8)$ & $5.0( \pm 0.8)$ & $4.5( \pm 1.5)$ \\
Deprived (Pep) & $-16.1( \pm 5.6)$ & $-19.8( \pm 4.3)$ & - & $-3.7( \pm 1.9)$ \\
Reopened (Pep) & $+23.3( \pm 5.1)$ & $+36.3( \pm 13.7)$ & - & $+3.0( \pm 0.8)$ \\
Normal control (IAA) & $3.8( \pm 0.6)$ & $1.6( \pm 0.5)$ & $5.1( \pm 1.9)$ & $2.2( \pm 0.8)$ \\
Reopened (IAA) & $+17.7( \pm 2.9)$ & $+16.9( \pm 1.9)$ & - & $+3.3( \pm 0.8)$ \\
Normal control (Air) & $2.2( \pm 0.7)$ & $1.8( \pm 0.4)$ & - & $2.8( \pm 0.7)$ \\
Reopened (Air) & $+11.3( \pm 1.6)$ & $+12.6( \pm 0.8)$ & - & $+2.8( \pm 1.2)$
\end{tabular}

In the deprived group (peppermint exposed), 2-DG uptake in the glomerular and nerve layers of the normal bulb did not differ significantly from the values obtained from normal controls. Consequently, negative values denote a decrease in uptake in the deprived bulb relative to the contralatcral, normal bulb. In the reopened groups, short-term collodion occlusion of the normal naris during the odor test did not significantly alter uptake values in the glomerular and nerve layers of the ipsilateral normal bulb, though the occurrence of focal uptake was reduced. The positive values therefore denote an increase in uptake in the deprived bulbs relative to the contralateral, normal bulbs. The percent changes in focal glomerular uptake in bulbs ipsilateral to an occluded naris or stimulated with room air were not quantified. Pep, peppermint odor; IAA, isoamyl acetate odor; Air, nondeodorized room air. 

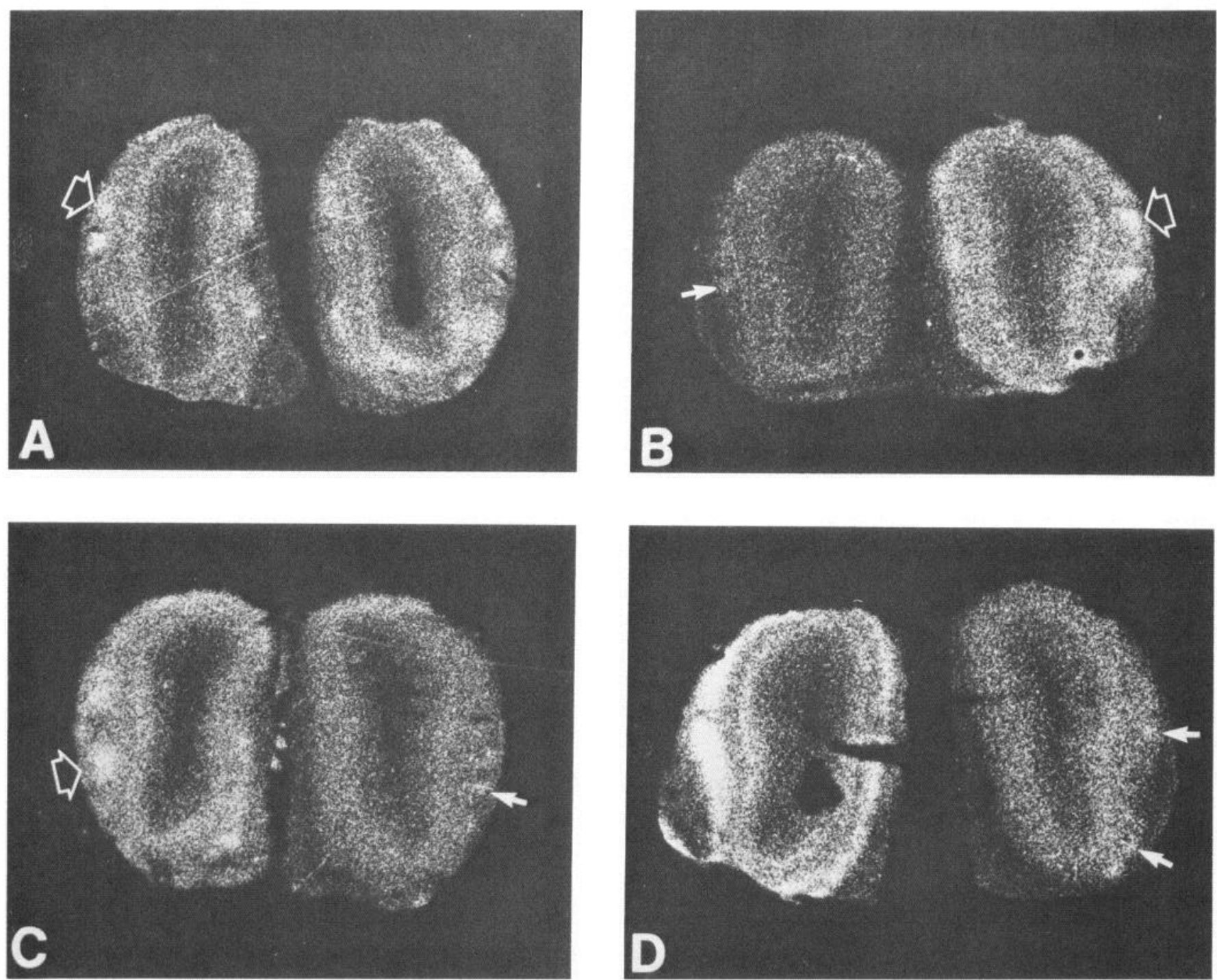

Figure 4. Autoradiograms of coronal olfactory bulb sections from 21-d-old animals given ${ }^{14} \mathrm{C}-2$-DG prior to exposure to peppermint odor. Open arrows indicate odor foci in the GL. A, A section from a control animal. B, A section from an animal that had its left naris occluded at PN2. The left naris remained sealed during the odor test. $C$ and $D$, Autoradiograms from unilaterally deprived rats that were given the odor test after the occluded naris $(C$ and $D$, left $)$ was reopened. The deprived bulbs in these animals demonstrate greater 2-DG uptake in the GL, and the odor foci appear somewhat larger than normal. Solid arrows indicate odor foci in bulbs ipsilateral to a sealed naris.

along the medial aspect of the bulb. Mitral/tufted cells in deprived and control pups did not significantly differ in terms of antidromic activation latency $(2.2 \pm 0.3 \mathrm{msec}$ vs $2.9 \pm 0.3$ msec, control vs deprived, respectively). However, the spontaneous activity rate during normal respiration of filtered air was significantly higher in control bulbs than in deprived bulbs. In control bulbs, the mean spontaneous activity rate was $7.2 \pm$ $0.5 \mathrm{~Hz}$. This corresponds well with rates previously reported for PN20 mitral/tufted cells (7.0 Hz; Wilson and Leon, 1986). There was, however, a significant reduction in spontaneous activity rates in deprived bulbs, with a mean rate of $5.5 \pm 0.5 \mathrm{~Hz}$ $[t(98)=2.19, p<0.05]$.

Mitral/tufted-cell single-unit responses to odor in deprived bulbs did not differ qualitatively from those recorded in normal bulbs. Mitral/tufted cells in normally respiring rats at this age typically demonstrate either an increase in firing rate during an odor stimulus, a decrease in firing rate during the stimulus, or no change (Mair, 1982; Mair and Gesteland, 1982; Wilson et al., 1987). Each of these response types could be identified in cells of the deprived bulb and in similar proportions to controls (Figs. 7-9). In response to the peppermint test odor, for example, the ratio of excitatory responses to the total response rate was 0.68 in control pups and 0.70 in deprived pups. Similarly, in the subset of cells also tested with isoamyl acetate ( 38 deprived cells, 30 control cells), the excitation ratio for control bulbs was 0.72 and was 0.68 for deprived bulbs (Fig. 9). Therefore, the proportion of excitatory and suppressive responses to odors was not significantly affected by early olfactory deprivation.

Interestingly, the total response rate to odors was significantly enhanced by deprivation (Fig. 9). Peppermint stimuli elicited responses in $29.1 \%$ of the cells encountered in control bulbs, while in deprived bulbs, $43.9 \%$ of the cells responded to peppermint stimuli $\chi^{2}=4.72, p<0.05$ ). A similar enhancement was seen in response to isoamyl acetate odor $\left(\chi^{2}=3.03, p<\right.$ 0.05 ; control response rate $=18.0 \%$, deprived response rate $=$ $28.4 \%)$. 

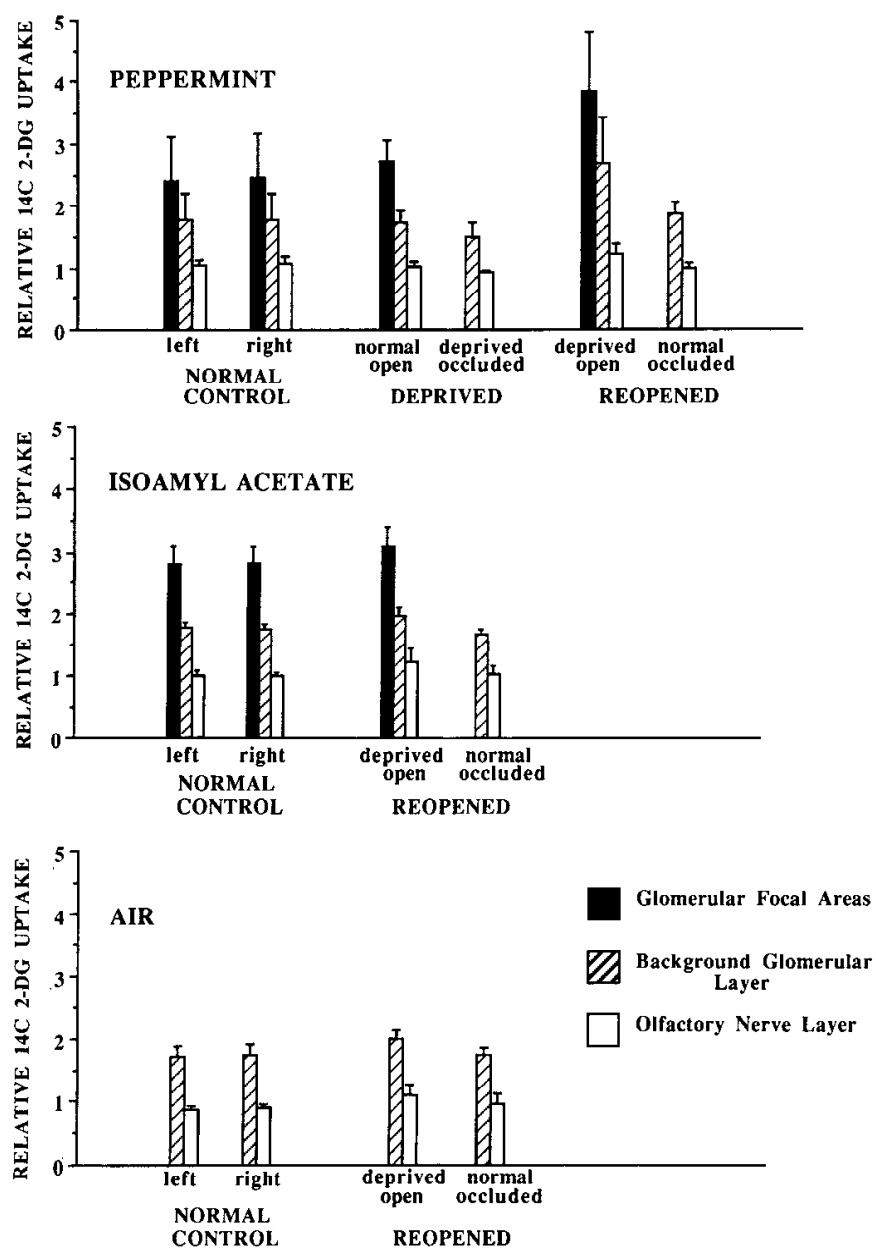

Figure 5. Comparison of relative ${ }^{14} \mathrm{C}$-2-DG uptake levels in olfactory bulbs of rat pups exposed to peppermint odor, isoamyl acetate odor, or room air. Experimental animals in the deprived group were subjected to naris occlusion on PN2 and odor tested at PN20-22. Pups in the reopened groups were treated similarly, but the occluded naris was surgically reopened prior to the odor test. Focal uptake in the GL in response to room air, when it occurred, was not quantified, nor was focal uptake in bulbs ipsilateral to an occluded naris. Note the increase in 2-DG uptake in deprived bulbs ipsilateral to a reopened naris.

\section{Glomerular layer TH immunoreactivity}

The immunohistochemistry confirmed the effectiveness of naris occlusion in altering bulb neurochemistry. GL TH immunoreactivity was substantially reduced in the deprived bulb of all our experimental animals compared to both the contralateral, nondeprived bulb and the bulbs of normal control pups (Fig. 10). Staining was consistently reduced in medial areas, but small areas of staining occasionally persisted in more ventrolateral regions. The pattern and intensity of $\mathrm{TH}$ immunoreactivity in the nondeprived bulbs of experimental animals did not appear to differ qualitatively from that of normal controls.

\section{Discussion}

Early olfactory deprivation during the first 3 postnatal weeks significantly modifies olfactory bulb function. Deprived bulbs are modified in several ways. The basal activity rate of mitral/ tufted cells is decreased compared to that recorded in normal bulbs. With the restoration of odor stimulation, both laminar 2-DG uptake and the incidence of odor-responsive mitral/tufted
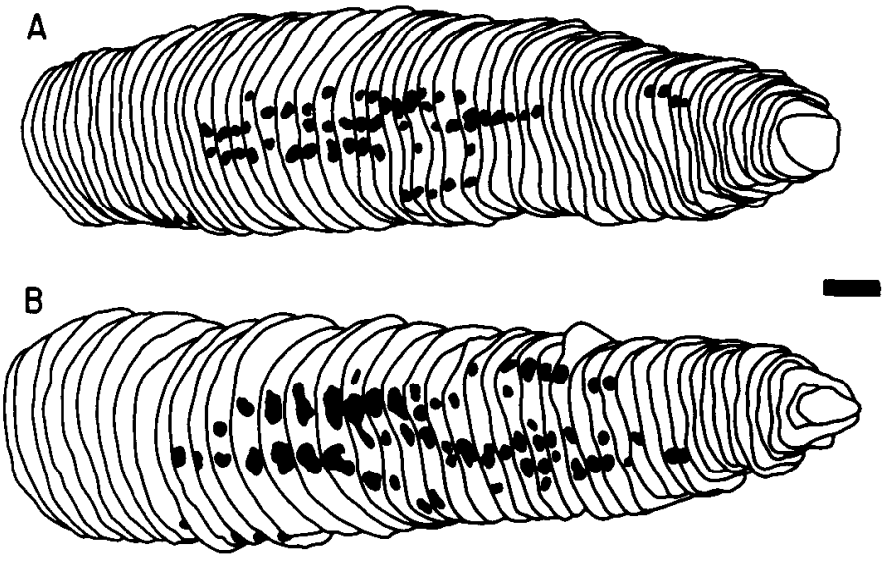

Figure 6. Serial reconstructions of a normal control $(A)$ and a deprived $(B)$ olfactory bulb showing distribution of focal areas of high 2-DG uptake within the lateral GL in response to peppermint odor. The occluded naris of the deprived animal was surgically reopened prior to the odor test. Drawings of individual sections were made from autoradiograms displayed on an imaging monitor. The ONL has been omitted to facilitate viewing of the odor foci. Dorsal is $u p$ and rostral is to the right. Note the difference in the size of the focal areas between the normal and deprived bulb. Scale bar, $1 \mathrm{~mm}$.

cells are significantly increased in deprived bulbs at PN20-22. Differences in respiration cannot account for these changes. The odor-specific spatial pattern of focal 2-DG uptake in the GL of the deprived bulb is largely retained, with different odors producing relatively specific spatial patterns. However, the odorresponsive foci often appear to encompass somewhat larger, less discrete regions of the GL compared to foci in normal bulbs.

Despite the increase in odor responsiveness, the characteristics of individual single-unit odor responses are not detectably changed by early deprivation using the methods described here. Deprived mitral/tufted cells exhibit both excitatory and suppressive responses to odors, and the ratio of excitatory to suppressive responses is unchanged. Of particular interest is the lack of a significant deprivation effect on suppressive responses. In the turtle olfactory bulb, evoked field potentials, indicative of granule cell responses, are reduced by dopamine (Nowycky et al., 1983). This is attributed to the suppression of mitral cell responses, which in turn decreases granule cell excitation via dendrodendritic synapses. However, even though the expression of the catecholamine-synthesizing enzyme TH is markedly reduced in dopaminergic glomerular neurons in deprived bulbs, there is no detectable effect on the occurrence or general characteristics of mitral/tufted cell suppressive responses to odors. Deprivation does not appear to affect the expression of GABAergic traits in the olfactory bulb (Kosaka et al., 1987), suggesting that suppressive responses in deprived bulbs may be mediated by GABA.

In the rat, the behavioral consequences of early olfactory deprivation, followed by naris reopening, are not known. Although focal glomerular 2-DG uptake is increased in the deprived bulb, so too is the background glomerular uptake. In fact, the ratio of focal GL 2-DG uptake relative to uptake in other areas of the GL is not modified by deprivation (mean ratios: control open $=1.38 \pm 0.51$, deprived open $=1.48 \pm 0.75$; NS). If the differences in activity between spatially distinct focal and nonfocal areas of the GL play a role in the detection or "coding" of olfactory information, it is unclear how the changes we ob- 
1

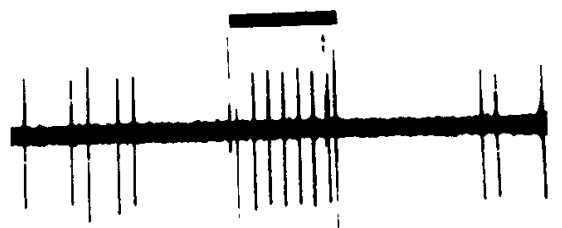

2

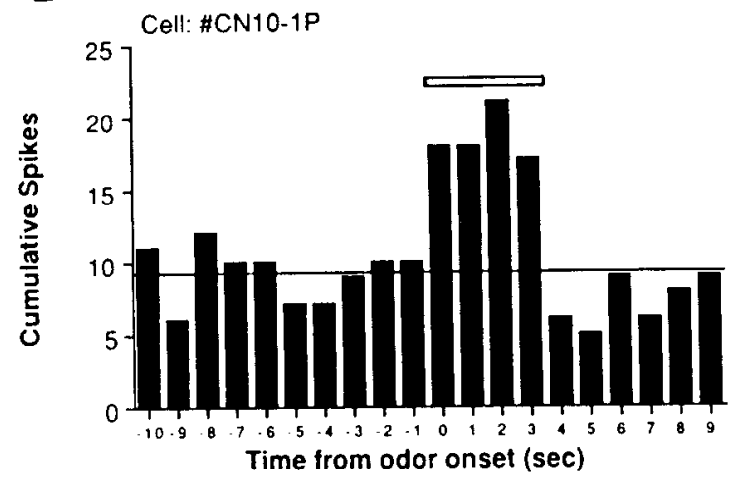

3

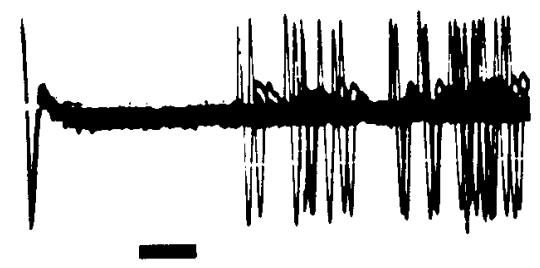

4

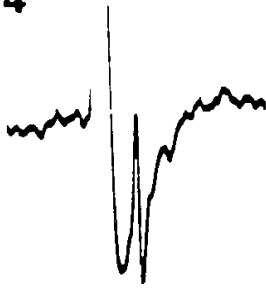

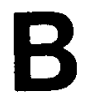

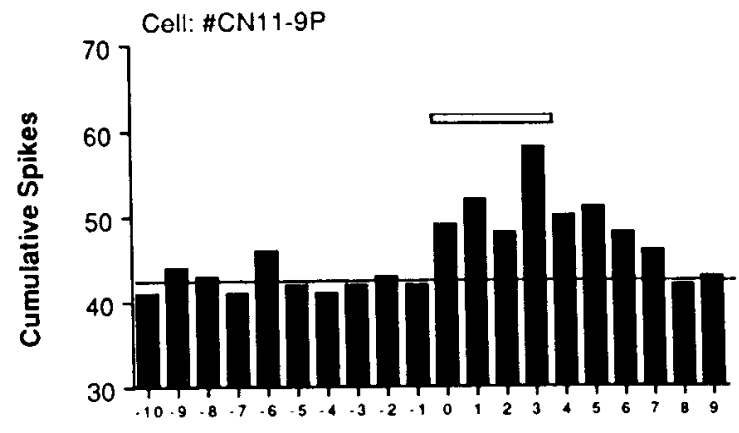

Time from odor onset (sec)
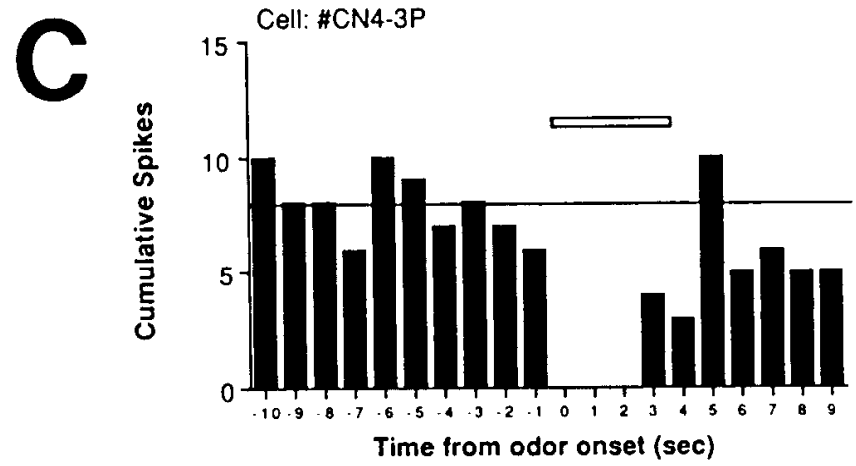

Figure 7. Examples of mitral/tufted-cell single-unit responses to odors recorded in olfactory bulbs deprived of stimulation from PN2 to PN2022. The ipsilateral naris was reopened prior to recording. Mitral/tufted cells displayed excitatory $(A$ and $B)$ and suppressive responses $(C)$ to odor. The odor stimulus was presented during the interval represented by the horizontal bar above the histograms $(A 2, B, C)$ and the recording trace (AI; artifacts produced by the odor-switching solenoid occur at the onset and offset of the odor stimulus). Recordings were verified as single-unit recordings by the occurrence of a relative refractory period, during which the cell is subject to recurrent inhibition by granule cells following spontaneous action potentials $(A 3)$ and by stable LOT antidromic latencies. Mitral/tufted cells were identified by antidromic activation from the LOT, as described in Materials and Methods (A4). Odor stimulus duration was $4 \mathrm{sec}$. Time scale in $A 3$ and $A 4$ is $5 \mathrm{msec}$.

served in the deprived bulb would influence olfactory coding or sensitity. The increased odor responsiveness may result in greater sensitivity, while the changes in focal 2-DG uptake patterns may indicate altered discriminatory ability. Of particular interest is the demonstration of olfactory-guided behavior in young, odor-deprived rabbits (Stahl et al., 1990). Following early unilateral olfactory deprivation, these animals respond normally to the presence of nipple-search pheromone after the occluded naris has been reopened and the normal bulb ablated.

The maintenance of bulb responsiveness in the absence of odor stimulation may be of critical importance during early development and throughout an animal's lifetime, given that mature olfactory receptor neurons are continually replaced by basal cells of the olfactory epithelium (Monti Graziadei and Graziadei, 1979; Graziadei and Monti Graziadei, 1980; Samanen and Forbes, 1984). Individual bulb neurons may be repeatedly temporarily deprived of peripheral input as receptor cells are lost and subsequently replaced. In the weanling rat, bulb neurons may receive peripheral afferents from as many as
250 receptor neurons, so complete deafferentation probably does not occur under normal circumstances (Meisami, 1989). Even so, olfactory bulb neurons may be uniquely adapted to withstand relatively brief periods of reduced stimulation without loss of functional capabilities.

\section{Potential mechanisms}

The mechanisms underlying the enhancement of bulb responses seen with odor deprivation are not yet known, and factors at several levels in the olfactory pathway may be involved. Bulb function is dependent on olfactory nerve input, intrinsic ncurons, and centrifugal afferents from a variety of central structures (Shepherd, 1972). Therefore, the changes observed here may reflect changes within the deprived bulb itself, changes in the activity of inputs to the bulb, or a combination of these factors. In addition, both odorant and nonodorant forms of stimulation are reduced by naris occlusion. The movement of air through the nasal passage provides for mechanical as opposed to sensory stimulation of the olfactory epithelium, and there is evidence 
A
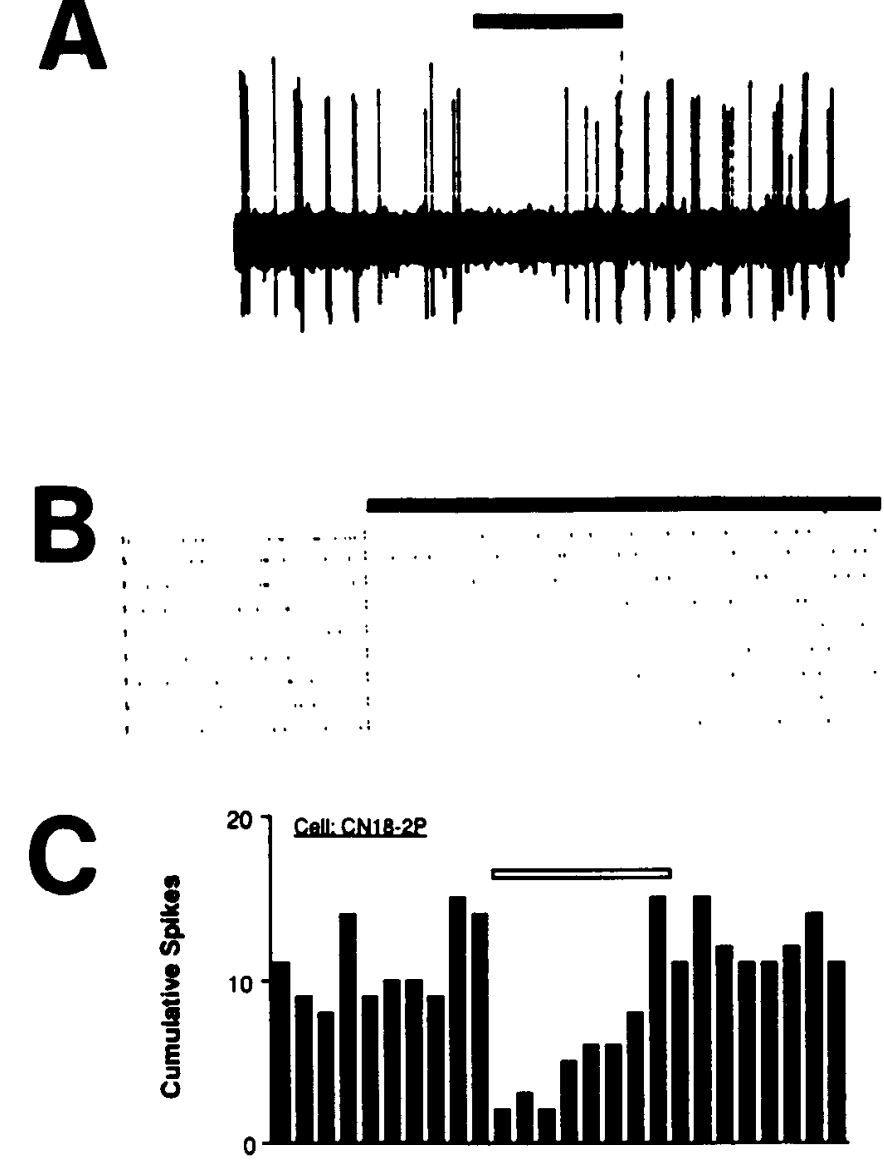

Figure 8. Mitral/tufted-cell single-unit responses to peppermint recorded in deprived bulb ipsilateral to reopened naris. This cell was consistently suppressed by peppermint odor, as shown in the raster dot display $(B)$ and the histogram $(C)$. The odor stimulus was presented during the interval indicated by the horizontal bar $(4 \mathrm{sec})$.

that reduced airflow, apart from odor deprivation, affects the development of both the olfactory and respiratory epithelia (Farbman et al., 1988; Stahl et al., 1990). We attempted to evaluate the separate effects of airflow and odor stimulation by testing animals with room air, but the occurrence of focal glomerular 2-DG uptake in these animals suggests that some odor stimulation was present during the 2-DG test. Moreover, odorant access, mucus secretion, and the dynamics of airflow may differ in reopened and normal nasal passages. At present, we cannot rule out the possibility that the mechanical effects of resumed airflow or the surgical procedure per se contributed to the responses we observed.

The increased odor responsiveness of the deprived bulb could reflect the effects of deprivation on the development and function of the olfactory receptor neurons, and the 2-DG data for the ONL support this possibility. GL 2-DG uptake appears to be largely dependent on afferent nerve activity; uptake increases following electrical stimulation of the olfactory nerve and is virtually eliminated by chemical lesioning of the olfactory epithelium (Greer et al., 1981; Astic and Cattarelli, 1982; Stewart et al., 1983). While the alterations in the intensity and pattern of bulb odor responses reported here might be due to changes in the number of functional olfactory nerve fibers, it has previously been shown that naris occlusion does not significantly alter the number of mature receptor neurons present in the
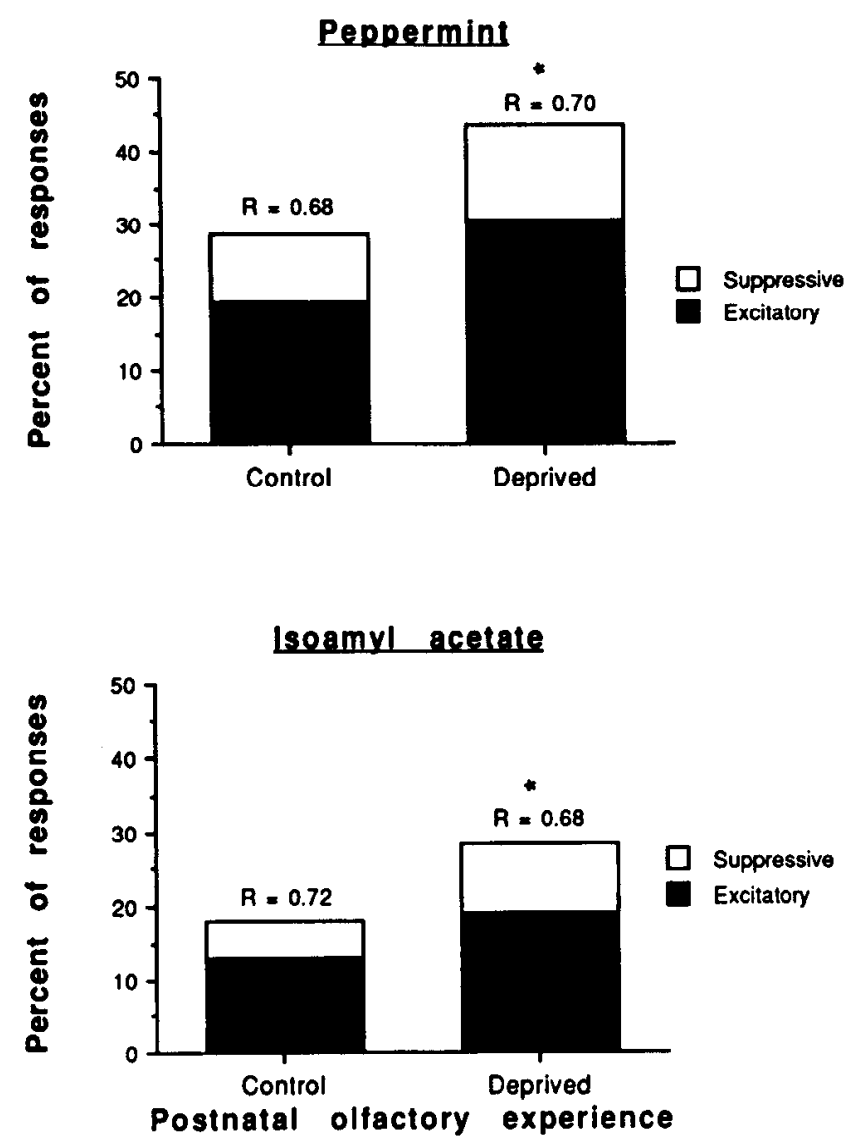

Figure 9. Mitral/tuftcd-cell single-unit response pattern to peppermint or isoamyl acetate odor in deprived and control bulbs. There was a significant increase in the incidence of mitral/tufted-cell odor responses in deprived bulbs following naris reopening compared to normal control bulbs. However, the ratio of excitatory to inhibitory responses $(R)$ was unaffected by deprivation. Asterisk, significantly different from control, $p<0.05$.

deprived epithelium (Benson et al., 1984; Farbman et al., 1988). However, as olfactory nerve projections undergo substantial postnatal development, sensory deprivation may affect their developing anatomical distribution or synaptic density within the GL (Hinds and Hinds, 1976; Hinds and McNelly, 1981; Brunjes and Frazier, 1986; Meisami, 1989).

Postnatal visual experience is known to play an important role in both the anatomical and functional development of ocular dominance columns in the cat visual cortex (Hubel and Wiesel, 1963; Shatz and Stryker, 1978). While there is general agreement that some degree of functional topography exists in the arrangement of receptor projections to the olfactory bulb, the role of postnatal sensory experience in establishing this topography is unknown. In the neonate, odor stimulation produces focal glomerular 2-DG uptake, but different odors do not produce distinguishably different uptakc patterns (Astic and Saucier, 1982). These patterns appear to change with age, with more foci apparent at later ages and stimulation with different odors eventually producing different patterns. Additionally, the foci in neonates appear to encompass more glomeruli than do the foci seen in weanling rats. It has been suggested that the progressive restriction of 2-DG foci to smaller areas of the GL could result from either the postnatal development of inhibitory periglomerular neurons or the rearrangement and gradual sta- 


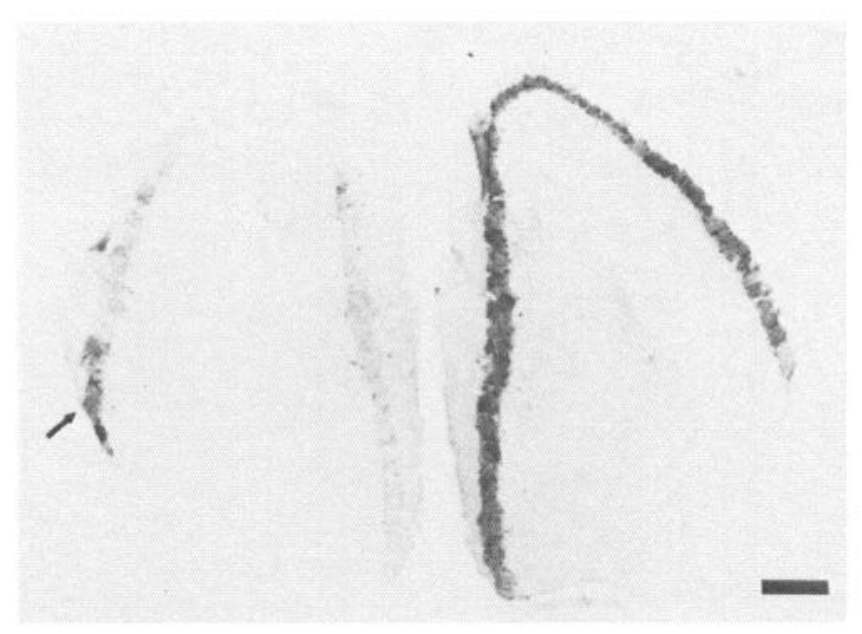

Figure 10. Photomicrograph of horizontal bulb section from unilaterally deprived animal, stained for TH immunoreactivity. TH immunoreactivity is markedly reduced in the GL of the deprived (left) bulb. Note the persistence of lateral staining (arrow). Scale bar, $500 \mu \mathrm{m}$.

bilization of synaptic connections between incoming olfactory nerve fibers and the dendrites of bulbar target neurons (Astic and Saucier, 1982). The appearance of odor-specific patterns of 2-DG uptake in deprived bulbs described in the present study suggests that at least some functional topography of the afferent input develops and is maintained during the first few postnatal weeks in the absence of normal sensory experience. The larger, less discreet appearance of the foci we observed in some deprived bulbs may reflect retarded maturation of the normal topography, but whether this is due to altered development of periglomerular circuitry or glomerular synaptic organization requires further study.

Lack of normal stimulation during development may also affect the response characteristics of individual receptor neurons. The deprived olfactory bulb exhibits greater density of spiperone (dopamine $\mathrm{D}_{2}$ receptors) and NGF binding sites than normal (Guthrie et al., 1987; Gomez-Pinilla et al., 1989), and similar changes in the number, affinity, and/or selective properties of odorant binding sites on deprived receptor cells may occur such that functional odor sensitivity and/or selectivity are altered. Changes in the odor responses of receptor neurons are known to occur during development, but the effects of deprivation on their response properties have not been examined (Gesteland et al., 1982).

Stimulation of centrifugal afferents has been shown to modulate olfactory bulb physiology (Nakashima et al., 1978; Nickell and Shipley, 1988). Consequently, deprivation-related changes in centrifugal mechanisms might also contribute to altered odor responsiveness. Bulbar levels of norepinephrine, derived from locus coeruleus afferents, are not significantly altered by deprivation (Brunjes et al., 1985), nor is the anatomical structure of the anterior olfactory nucleus (Brown and Brunjes, 1989), but the effects on other centrifugal structures that project to the olfactory bulb, such as the pyriform cortex, the nucleus of the horizontal limb of the diagonal band, and the raphe nucleus, have not been evaluated.

Another potential mechanism relates to the dramatic reduction of $\mathrm{TH}$ immunoreactivity in the glomerular region of de- prived bulbs and the accompanying decrease in bulb dopamine levels. At PN20, the concentration of dopamine in deprived bulbs is significantly reduced compared to normal bulbs (Brunjes et al., 1985). Dopamine antagonists have been shown to enhance olfactory bulb responses to olfactory nerve stimulation and increase LOT paired-pulse inhibition in the in vitro turtle olfactory bulb (Nowycky et al., 1983). If dopaminergic juxtaglomerular neurons contribute to lateral inhibition in the GL, this inhibition should be reduced in deprived bulbs. The increases observed in both glomerular 2-DG uptake and the incidence of mitral/ tufted-cell responses during odor stimulation support this hypothesis. Moreover, inhibition of mitral cells following pairedpulse stimulation of the LOT is enhanced in deprived, dopamine-depleted bulbs (D. A. Wilson, K. M. Guthrie, and M. Leon, unpublished observations). This corresponds very well with the enhanced LOT paired-pulse inhibition observed with dopamine antagonists (Nowycky et al., 1983). Previous work in our laboratory has provided evidence of lateral synaptic interactions in the olfactory bulb, and a comparison of these traits in normal and deprived bulbs may help determine the contribution of the dopaminergic system to lateral inhibition in the bulb (Wilson and Leon, 1987).

Although we attempted to examine the effects of deprivation prior to the appearance of much of the deprivation-induced neuroanatomical changes, we cannot rule out the possibility that early cell death contributed to the functional changes described here. Studying the effects of deprivation at several different ages might help distinguish the relative contributions of dopamine depletion and anatomical changes to olfactory bulb function. For example, unilateral olfactory deprivation in mature animals also reduces $\mathrm{TH}$ immunoreactivity but does not result in significant structural modification of the bulb (Brunjes and Borror, 1983; Kosaka et al., 1987). In addition, the loss of TH immunoreactivity appears to be at least partially reversible with resumed stimulation (Kosaka et al., 1987). By maintaining the reopened naris for longer periods of time, the functional effects of deprivation reversal can also be examined.

In conclusion, our data demonstrate that early unilateral naris occlusion results in functional changes in the deprived ipsilateral olfactory bulb. Odor responsiveness appears to be enhanced rather than diminished. Just as a deeper understanding of the functional organization of the visual system has emerged from studies of early visual deprivation, an exploration of deprivation effects on the function of both peripheral and central structures in the olfactory pathway may lead to a better understanding of the mechanisms involved in the coding and processing of olfactory stimuli.

\section{References}

Astic L, Cattarelli M (1982) Metabolic mapping of functional activity in the rat olfactory system after a bilateral transection of the lateral olfactory tract. Brain Res 245:17-25.

Astic L, Saucier D (1982) Ontogenesis of the functional activity of the rat olfactory bulb: autoradiographic study with the 2-deoxyglucose method. Dev Brain Res 2:243-256.

Baker H (1986) Neonatal olfactory deprivation results in a dramatic reduction of tyrosine hydroxylase levels in the adult rat main olfactory bulb. Am Chem Soc Abstr 8:167.

Benson TE, Ryugo DK, Hinds JW (1984) Effects of sensory deprivation on the developing mouse olfactory system: a light and electron microscopic, morphometric analysis. J Neurosci 4:638-653. 
Brown JL, Brunjes PC (1989) Development of the anterior olfactory nucleus in normal and unilaterally odor deprived rats. Am Chem Soc Abstr 11:179.

Brunjes PC, Borror MJ (1983) Unilateral odor deprivation: differential effects due to time of treatment. Brian Res Bull 11:501-503.

Brunjes PC, Frazier LL (1986) Maturation and plasticity in the olfactory system of vertebrates. Brain Res Rev 11:1-45.

Brunjes PC, Smith-Crafts LK, McCarty R (1985) Unilateral odor deprivation: effects on the development of olfactory bulb catecholamines and behavior. Dev Brain Res 22:1-6.

Coopersmith R, Leon M (1984) Enhanced neural response to familiar olfactory cues. Science 225:849-851.

Cullinan WE, Brunjes PC (1987) Unilateral odor deprivation: effects on the development of staining for olfactory bulb succinate dehydrogenase. Dev Brain Res 35:35-42.

Durham D, Woolsey TA (1984) Effects of neonatal whisker lesions on mouse central trigeminal pathways. J Comp Neurol 223:424-447.

Farbman AI, Brunjes PC, Rentfro L, Michas J, Ritz S (1988) The effect of unilateral naris occlusion on cell dynamics in the developing rat olfactory epithelium. J Neurosci 8:3290-3295.

Frazier LL, Brunjes PC (1988) Unilateral odor deprivation: early postnatal changes in olfactory bulb cell density and number. J Comp Neurol 269:355-370.

Garey LJ, Blakemore C (1977) Monocular deprivation: morphological effects on different classes of neurons in the lateral geniculate nucleus. Science 195:414-416.

Gesteland RC, Yancey RA, Farbman AI (1982) Development of olfactory receptor neuron selectivity in the rat fetus. Neuroscience 7: 3127-3136.

Gomez-Pinilla F, Guthrie KM, Leon M, Nieto-Sampedro M (1989) NGF receptor increase in the olfactory bulb of the rat after early unilateral deprivation. Dev Brain Res 48:161-165.

Graziadei PPC, Monti Graziadei GA (1980) Neurogenesis and neuron regeneration in the olfactory system of mammals. III. Deafferentation and reinnervation of the olfactory bulb following section of the fila olfactoria in the rat. J Neurocytol 9:145-162.

Greer CA, Stewart WB, Kauer JS, Sheperd GM (1981) Topographical and laminar localization of 2-deoxyglucose uptake in rat olfactory bulb induced by electrical stimulation of olfactory nerves. Brain Res 217:279-293.

Guthrie KM, Leon M (1989) Induction of tyrosine hydroxylase expression in rat forebrain neurons. Brain Res 497:117-131.

Guthrie KM, Pullara JM, Marshall JF, Leon M (1987) Olfactory deprivation increases $\left[{ }^{3} \mathrm{H}\right]$-spiroperidol binding in the rat olfactory bulb. Soc Neurosci Abstr 13:1403.

Hinds JW, Hinds PL (1976) Synapse formation in the mouse olfactory bulb. I. Quantitative studies. J Comp Neurol 169:15-35.

Hinds JW, MoNelly NA (1981) Aging in the rat olfactory system correlation of changes in the olfactory epithelium and olfactory bulb. J Comp Neurol 203:441-453.

Hubel DH, Wiesel TN (1970) The period of susceptibility to the physiological effects of unilateral eye closure in kittens. J Physiol (Lond) 206:419-436.

Jourdan F, Duveau L, Astic L, Holley A (1980) Spatial distribution of $\left[{ }^{14} \mathrm{C}\right] 2$-deoxyglucose uptake in the olfactory bulbs of rats stimulated with two different odours. Brain Res 188:139-154.

Knudsen EI, Esterly SD, Knudsen PF (1984) Monaural occlusion alters sound localization accuracy during a sensitive period in the barn owl. J Neurosci 4:1001-1011.

Kosaka T, Kosaka K, Hama K, Wu J-Y, Nagatsu I (1987) Differential effect of functional olfactory deprivation on the GABAergic and catecholaminergic traits in the rat main olfactory bulb. Brain Res 413 197-203.

Mair RG (1982) Response properties of rat olfactory bulb neurones. J Physiol (Lond) 326:341-359.

Mair RG, Gesteland RC (1982) Response properties of mitral cells in the olfactory bulb of the neonatal rat. Neuroscience 7:3117-3125.

Math F, Davrainville JL (1980) Electrophysiological study on the postnatal development of mitral cell activity in the rat olfactory bulb. Brain Res 190:243-247.

Meisami E (1976) Effects of olfactory deprivation on postnatal growth of the rat olfactory bulb utilizing a new method for production of neonatal unilateral anosmia. Brain Res 107:437-444.

Meisami E (1989) A proposed relationship between increases in the number of olfactory receptor neurons, convergence ratio and sensitivity in the developing rat. Dev Brain Res 46:9-19.

Meisami E, Noushinfar E (1986) Early olfactory deprivation and the mitral cells of the olfactory bulb: a Golgi study. Int J Dev Neurosci $4: 431-444$.

Meisami E, Safari L (1981) A quantitative study of the effects of early unilateral olfactory deprivation on the number and distribution of mitral and tufted cells and of glomeruli in the rat olfactory bulb. Brain Res 221:81-107.

Monti Graziadei GA, Graziadei PPC (1979) Neurogenesis and neuron regeneration in the olfactory system of mammals. II. Degeneration and reconstitution of the olfactory sensory neurons after axotomy. $J$ Neurocytol 8:197-213.

Moore DR, Hutchings ME, King AJ, Kowalchuk N (1989) Auditory brain stem of the ferret: some effects of rearing with a unilateral ear plug on the cochlea, cochlea nucleus, and projections to the inferior colliculus. J Neurosci 9:1213-1222.

Mori K, Satou M, Takagi SF (1979) Axonal projection of anterior olfactory nuclear neurons to the olfactory bulb bilaterally. Exp Neurol 64:295-305.

Nakashima M, Mori K, Takagi SF (1978) Centrifugal influence on olfactory bulb activity in the rabbit. Brain Res 154:301-316.

Nickell WT, Shipley MT (1988) Ncurophysiology of the magnocellular forebrain inputs to the olfactory bulb in the rat: frequency potentiation of the field potentials and inhibition of output neurons. J Neurosci 8:4492-4502.

Nowycky MC, Halasz N, Shepherd GM (1983) Evoked field potential analysis of dopaminergic mechanisms in the isolated turtle olfactory bulb. Neuroscience 8:717-722.

Pasic TR, Rubel EW (1989) Rapid changes in cochlear nucleus cell size following blockade of auditory nerve electrical activity in gerbils. J Comp Neurol 283:274-480.

Robertson D, Irvine DRF (1989) Plasticity of frequency organization in auditory cortex of guinca pigs with partial unilateral deafness. J Comp Neurol 282:456-471.

Royet JP, Sicard G, Souchier C, Jourdan F (1987) Specificity of spatial patterns of glomerular activation in the mouse olfactory bulb: computer-assisted image analysis of 2-DG autoradiograms. Brain Res 417: $1-11$.

Samanen DW, Forbes WB (1984) Replication and differentiation of olfactory receptor neurons following axotomy in the adult hamster: a morphometric analysis of postnatal neurogenesis. J Comp Neurol 225:201-211.

Sharp FR, Kauer JS, Shepherd GM (1975) Laminar analysis of 2-deoxyglocose uptake in olfactory bulb and olfactory cortex of rabbit and rat. J Neurophysiol 40:800-813.

Shatz CJ, Stryker MP (1978) Ocular dominance in layer IV of the cat's visual cortex and the effects of monocular deprivation. J Physio (Lond) 281:267-283.

Shepherd GM (1972) Synaptic organization of the mammalian olfactory bulb. Physiol Rev 52:864-917.

Skeen LC, Due BR, Douglas FE (1985) Effects of early anosmia on two classes of granule cells in developing mouse olfactory bulbs. Neurosci Lett 54:301-306.

Skeen LC, Due BR, Douglas FE (1986) Neonatal sensory deprivation reduces granule cell number in mouse olfactory bulbs. Neurosci Lett 63:5-10.

Stahl B, Hudson R, Distel H (1990) Effects of reversible nare occlusion on the development of the olfactory epithelium in the rabbit nasal septum. Cell Tissue Res 259:275-281.

Stewart WB, Kauer JS, Shepherd GM (1979) Functional organization of rat olfactory bulb analysed by the 2-deoxyglocose method. J Comp Neurol 185:715-734

Stewart WB, Greer CA, Teicher MH (1983) The effect of intranasal zinc sulfate treatment on odor-mediated behavior and on odor-induced metabolic activity in the olfactory bulbs of neonatal rats. Dev Brain Res 8:247-259.

Van der Loos H, Woolsey TA (1973) Somatosensory cortex: structural alterations following early injury to sense organs. Science 179:395398.

Wiesel TN, Hubel DH (1963a) Effects of visual deprivation on morphology and physiology of cells in the cat's lateral geniculate body. $\mathrm{J}$ Neurophysiol 26:978-993.

Wiesel TN, Hubel DH (1963b) Single-cell responses in striate cortex 
of kittens deprived of vision in one eye. J Physiol (Lond) 26:289292.

Wilson DA, Leon $M$ (1986) Early appearance of inhibition in the neonatal rat olfactory bulb. Dev Brain Res 26:289-292.

Wilson DA, Leon M (1987) Evidence of lateral synaptic interactions in the olfactory bulb output cell responses to odor. Brain Res 417: $175-180$.
Wilson DA, Leon M (1988) Spatial patterns of olfactory bulb singleunit responses to learned olfactory cues in young rats. J Neurophysiol 59:1770-1782.

Wilson DA, Sullivan RM, Leon M (1987) Single-unit analysis of postnatal olfactory learning: modified olfactory bulb output response patterns to learned attractive odors. J Neurosci 7:3154-3162. 